International Journal of Engineering \& Technology, 9(3) (2020) 665-669
International Journal of Engineering \& Technology
SPC
Website: www.sciencepubco.com/index.php/IJET
Research paper

\title{
Virtual reality and augmented reality create fair education opportunities for refugee children in camps
}

\author{
Abdulrazak M. Aman ${ }^{1 *}$, Norshuhada Shiratuddin ${ }^{1}$ \\ ${ }^{1}$ School of Multimedia Technology and Communication, Universiti Utara Malaysia, Sintok, Malaysia \\ *Corresponding author E-mail: abdulrazak.aman@outlook.com
}

\begin{abstract}
In this article, it is reported about Virtual Reality and Augmented Reality, its impact on the technology world, and change it induced in the digital world. Virtual Reality is the next step in the evolution of technology, changing the face of technology, and whole new experience. Virtual Reality and Augmented Reality changing people's daily lives and serving the helpless beings on the planet. Hence, helping to improve the educational system, introducing an innovative and compulsive method of teaching, creating new opportunities for helping out the refugee children in refugee children with lesser resources and opportunities. Identifying the current problems in the educational system, virtual Reality, and augmented Reality, providing solutions for the pre-existing problems in the system. Use of VR and AR for students with fewer resources to increase their exposure to the world. Conducting Virtual Reality trips, VR education in refugee camps, and use of VR to reach out to children with no formal education. Use of VR for educational purposes for refugee children and teachers in Turkey, Germany, Syria, Jordan, and all over the globe. Future of VR and AR, its impact on the world in the coming years, providing a completely new experience and visualization of the digital world.
\end{abstract}

Keywords: Virtual Reality; Augmented Reality; Refugee Camps; Refugee Children; VR Trips; Virtual World; Digital World; Education; Simulation; Simulated World.

\section{Introduction}

Augmented Reality and Virtual Reality are examples of the latest technology and its out of the world experience. Augmented Reality adds digital elements to our daily experience, often using the displays that are used to interact with the digital world. It combines different elements enhancing our view and adding compelling features that can be viewed through our screens (Gupton, 2017). Augmented Reality was the first step in the Virtual world, enhancing our digital world experience by adding different features that attract the masses. VR and AR, creating a whole new experience by introducing a feature that is interacting with the virtual world. Furthermore, visualizing the world with a new angle, virtual Reality was introduced to give a person an immersive feeling in the virtual world. VR and AR creating opportunities for children to widen their scope, increase their knowledge, maximize exposure to the outer world, and enhancing educational techniques. Education is the fundamental right of every human being, and that is how every single person adapts to the current world and strives to leave his mark. Using the latest technology, creating a simulated world for the user virtual reality provides a person a whole new world. A head-mounted display enables the person to enter the virtual world, which gives him the simulated world (Bardi, 2019). Virtual Reality giving the user a person a 3-D view of the simulated world with 3-D audio, which ultimately provides the person with immersed by the experience.

\section{Literature review}

In (Picheta, 2020) reports about the students in Kenya take a VR trip to London's national gallery and how the Virtual Reality benefits the children in Kenya. The children who do not have the resources to experience the art in London's national gallery but VR makes it possible for them. Refugees from Syria seeking shelter in Turkey are getting formal education and (Turkey: Refugee children build their own virtual reality city, 2018) shows how VR is an innovative way to attract students towards technology and how Turkey is implementing the use of technology to teach their children and the refugees. Virtual Reality is an ingenious way to attract the students, introducing smart learning, and developing their interest in the course. Education is essential for every single human being, and people in refugee camps are no exceptions (Brown, 2016) shows the ways how VR is revolutionizing approaches to provide education for the refugees. Refugees that fled Syria sought shelter in different countries such as Jordan, Turkey, Germany, and many others. (Beste, 2015) throws light on the Syrian refugee children in different countries and VR providing them remote education where formal education is not possible. The paper by Adam (Adams, 2016), shows how VR will completely change the world in the coming years. The complete revolution in every industry and many aspects of life that will be replaced entirely using VR. 


\section{How VR and AR changed the tech world}

A simulated experience that is very close to the real world has no limitations; it has changed the experience of the user of the digital world. Providing the user with a 3-D environment, it has attracted the whole world; the user experiences the real world like gestures. The environment generated through simulation can be realistic and including the fantasies which are not possible in the real-world; this provides the user an immersive experience. Sensors are also attached to Virtual Reality which, senses the actions in the real world, and their consequences are enacted accordingly in the virtual world; this gives the user the realistic experience of how his actions are simulated consequently in the virtual world. Virtual Reality and Augmented Reality have changed the tech world in the following aspects and many more,

- Diagnostics

- $\quad$ High-risk job training

- Cinema and entertainment

- Virtual tourism

- Surgeon and medical student training

- $\quad$ Shopping

\section{VR and AR changing the educational world}

Transfer of education all around the world has been the top priority; it helps build the nation and is the fundamental right of every civilian. Education forms a nation and is a road to success for the nation. Every nation invests a lot in their educational systems striving towards building a better society, enhancing the lifestyle of their people, progressing the technological world, and leading the race of technology. The educational system should be strategical and effective, should strive towards educating the students. Virtual Reality and Augmented Reality can generate interest and is an innovative way to transfer information to the students making it interesting for them. In this digital era, books are converting into the e-books, everything is transferred online, and new systems are being developed for the ease of students (Babich, 2019). A significant problem faced by the students is that the world is changing quickly due to technological advancements, but the educational formats and techniques are not being replaced. The students are being fed with facts and cramming them, which is quite different from educating them. Actual education and being informed about facts are two different things. In today's world, everything is just a click away, and education systems need to be reformed. Figure 1.1 shows the number of refugee children in different countries with no formal education.

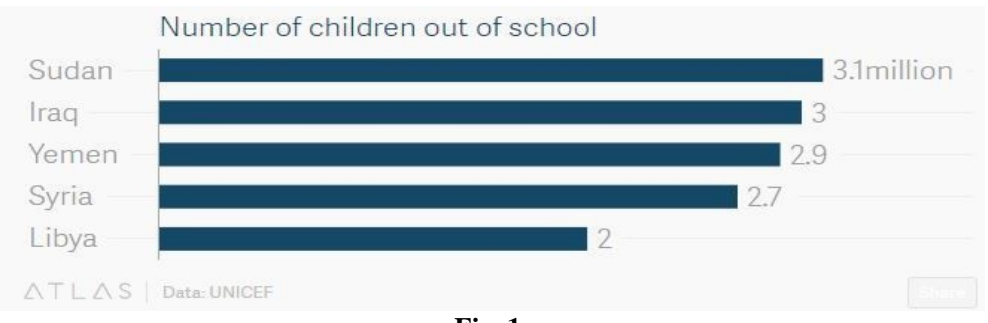

Fig. 1:

\section{VR and AR create opportunities for children in refugee camps}

Virtual Reality and Augmented Reality can enhance the learning of the students by engaging them in the virtual world. Educational systems can be reformed by providing students with VR and AR facilities. They are providing students with a virtual world where they can interact, perform actions, and educate themselves with experience. It will prevent them from cramming information, and they will learn while being immersed in the virtual world and experience. Educational systems can be converted entirely to Virtual Reality, providing students with a new exciting way to learn things, which will attract student's attention and draw him to learn more with surreal experiences and educational tours. Students can gain by performing experiments in the VR headset without the need for actual lab equipment. VR will provide students the opportunity to learn anything with real-lifelike experiences; it will widen their approach to more information allowing them to follow what they are interested in more.

With more than six hundred thousand refugees in Jordan, the global organization Mercy Corps and the University of Bradford built a VR pilot for the Syrian refugees. The children were provided with the VR equipment by them for educational purposes. The VR was also used to reconnect them to their homeland by providing them a simulated view of their country. Some ways VR and AR can change the educational systems are:

- A better sense of place

- Scale learning experiences

- Learn by doing

- Emotional reaction

- Develop creativity

- Visual learning

- Users are ready to embrace new technology

- Virtual field trips

- High tech training

- Internships

- Group learning

- Distance learning 
The refugee and children living in the war and conflict zones are living the worst lives, striving to stay alive; they are very far from education. Leaving their homes for various reasons, living in another country or region is a life-changing event for them. They have problems more significant than education, and staying alive and sane is a big issue. Providing them education is a big challenge faced by the modern world. In the conflict zones where the children's home is reduced to dust, and he is struggling to live, it is a huge problem providing them with proper education. If the children all around the world who are unable to attend school due to war and conflicts leading them to flee their country or home, the education should be brought to them (Brown, 2016). Fortunately, a few solutions are possible. Virtual education is the way to go for the education of refugee children. Schools can be brought to the children where the children cannot go the school.

\subsection{Refugee children in Syria}

Since 2011, over four million refugees have fled Syria due to the war and terrorism in the country. Over a million refugee children are not attending school (Beste, 2015), to deal with this issue, many NGOs, organizations are working to help the children attend schools and move schools to them. The Syrian refugee children were provided with the apps where they can participate in online classes and get an education online. Also, helping the children with psychosocial wellbeing considering the conditions they went through and are living through.

\subsection{A VR trip to London national gallery in Kenya}

The refugee children in Kenya using the VR technology visited London's national gallery on a school trip. The world's first Virtual reality trip, using the virtual headsets, attended a lecture at the London national gallery (Picheta, 2020). The students visited the gallery and explored the paintings hanging in London's national gallery. Virtual Reality gives the student a live visit to the gallery where they can have the experience of wandering around in a national gallery. Enjoying the real wandering feel in the gallery, watching paintings, and encounter them in a particular way. VR is providing the children with a completely new experience and learning method. The children experienced how it feels to visit a national gallery, widening their thinking and exposing them more to the outer world. Organizers used 360 degrees camera for the students to have the experience of their lifetime (Picheta, 2020).

\subsection{Refugee children in Jordan}

About $40 \%$ of the Syrian refugee children in Jordan are out of schools and don't have any formal education. Many barriers prevent children from Jordan from attending schools. Families and refugee children cannot afford to attend school. Around $15 \%$ of the refugee children living in the camps are out of school. (plan-international.org, n.d.). The international organizations, local NGOs, and the Lebanese government collaborate to provide the children with a flexible and innovative education, providing them with all the technology and bringing schools to them. Strengthening the literacy rate in the country, the Lebanese government provided children with VR headsets with all the information and books installed, enabling children to study by themselves and surf through the internet. Through the VR headsets, students can also attend online lectures where teachers can provide them with formal education.

\subsection{Refugee children in Lebanon}

The Syrian refugees fled their country and entered Lebanon. A huge number of refugees entering Lebanon meant that many children lost their schools. Lebanese ministry of education and higher education (MEHE) has maintained a three-year strategy by reaching all the schools to the refugee children. Remote places where the students cannot be provided with a school online education system and services are being offered. VR and AR systems are introduced for better learning systems, and children were presented with the material they needed. In Lebanon, the children were provided an online platform where the children could learn, and the adults could teach Arabic and any other courses they have mastered (Brown, 2016). Many organizations working for human rights and wellbeing helped refugees all around the world, providing them with online educations systems.

\subsection{Turkey refugee children build their own VR city}

Millions of refugees from Iraq and Syria fled their homes due to war and terror in their countries and found shelter and peace in Turkey. In Turkey, the refugee children were provided with formal education and innovative systems. The refugee children in Turkey, in a school project, developed a whole city in Virtual Reality. The Future Aleppo project lets refugee children build their cities in the simulation (Turkey: Refugee children build their own virtual reality city, 2018). The project hosts workshops that teach the children to build their Virtual cities by providing them with all the necessary equipment. Statistics of refugees in camps in Turkey, figure 1.2 below shows the percentages of people based on their education.




Fig. 2:

\subsection{German education adapting to include refugee children}

German unions are planning to adapt their education system in such a way that the refugee children can enter their schools and colleges quickly. The refugees can also get teaching jobs at their schools and colleges so that they can be included in society. The German union is planning to include training in language skills, which will teach the refugees their language to enhance understanding, as well as vocational, academic, and political education. Germany already including education through innovative ways such as introducing VR classrooms and organizing workshops on VR; the refugee children, if studying in the same school, will also get the same education.

\section{Future of VR and AR}

Virtual Reality and Augmented Reality have been in use for quite some time now, but still, it hasn't unveiled at its full potential in the market. It is undoubtedly something that seems futuristic and is going through the developing phase. Yet, once it is out there entirely, it can redesign the user experience and take it to a whole new level. It is set to dominate the technological landscape in the coming years (Adams, 2016). Virtual Reality is a complete experience as compared to the Augmented Reality that is set to dominate the world in the future. Everything consumed in the digital world will be changed entirely and will eventually switch to virtual Reality.

\subsection{Increase the ease of conceptualization}

The purpose picture or an image serves, giving a 2-D view of anything to create a concept of how the view looks in real life. Virtual Reality will enhance the user's experience by giving them a simulated or actual 3-D view of the scene; this will improve the conceptualization of the user and provide a look almost as good as real-life experience. A new building, a new house before construction, a simulation can be generated how everything will be constructed, this will provide a user a 3-D conceptualization of the house that yet to built, and he can set everything to his likings even before the house is built (Adams, 2016).

\subsection{Ease with learning new skills}

Military training can be done in the virtual Reality providing the soldiers with real-lifelike circumstances and training them for the worst. Training any student before going into real-life, he can gain skill and work in the simulated situation provided to him in the VR headset. A pilot, soldier, firefighter, the surgeon can use the VR simulation for training and experience situations in the VR headset, gaining experience, knowing how to handle any situation.

\subsection{Remote controlling}

When flying a drone, watching a screen with a limited vision can cause accidents. VR providing aa 3-D vision and giving the pilot a Firstperson view from the cockpit using the VR headset can enhance the experience and completely change the drone system (Adams, 2016). Even flying airplanes can be ultimately be shifted to VR and give pilots ease of flying the plane from anywhere. Not only drones, anything can be remotely controlled using VR headsets, providing the user a First-person view enables him to handle it with ease. Surgeries can be done from anywhere in the world, providing the person a 3-D view of the actual situations, and he can carry on the operation with his actions in one corner of the world and machine doing the enactment in the other corner.

\section{Foreign experiences}

By using Virtual Reality, 3-D experiences of roaming anywhere all around the world. The face of tourism can be changed completely; a person can visit anywhere in the world using his VR headset and have a real-lifelike experience using his VR headset. Replication of foreign maps and environments, creating an immersive experience for the user, who can visit any place in the world by just sitting in his room.

\section{Conclusion}

Virtual Reality and Augmented Reality, which is a new technological advancement in the digital world, is slowly changing everything. Virtual realities are already being used in many parts of the world for numerous purposes. Education systems can be entirely replaced by switching to Virtual Reality, by providing education to the children in refugee camps and in remote locations where there are no schools. The use of Virtual Reality can entirely flip marketing, tourism, training, the medical world, and many more aspects of life; it can enhance user experience and reduce risk in practice. Virtual Reality is the future; in the coming years, the world can completely shift to Virtual Reality, and our life will be more luxurious and comfortable. With more technological advancements, virtual Reality can provide any experience in the world with real-lifelike scenarios. It will change how the industries operate, healthcare and education systems, commerce, and entertainment experiences will be completely enhanced. Immersive environments and surreal experiences will enhance the human lifestyle, and technology will once again make our lives easier.

\section{Acknowledgement}

This is a text of acknowledgements. Do not forget people who have assisted you on your work. Do not exaggerate with thanks. If your work has been paid by a Grant, mention the Grant name and number here.

I would like to extend thanks to the many people, in many countries, who so generously contributed to the work presented in this paper. Special mention goes to Dr. Mohamed Aouf, Dr. Oussama Saoula. Finally, but by no means least, thanks go to mum, dad and I'd like to 
express my deepest gratitude to my wife, Ahlam Kahisaa. They are the most important people in my world and I dedicate this work to them.

\section{References}

[1] 6 Ways Virtual Reality is Changing the World. (2020, January 5). Retrieved from HP: https://store.hp.com/us/en/tech-takes/6-ways-vr-is-changingthe-world\#: :text=Virtual\%20reality\%20technology\%20allows\%20gamers,new\%20VR-enabled $\% 20$ gaming $\% 20$ experiences.

[2] Adams, R. (2016, October 17). Five Ways Virtual Reality Will Change The World. Retrieved from Forbes: https://www.forbes.com/sites/robertadams/2016/10/17/5-ways-virtual-reality-will-change-the-world/\#5d3915de2b01

[3] Babich, N. (2019, September 19). How VR In Education Will Change How We Learn And Teach. Retrieved from XD ideas: https://xd.adobe.com/ideas/principles/emerging-technology/virtual-reality-will-change-learn-teach/

[4] Bardi, J. (2019, 03, 26). What is Virtual Reality? Retrieved from marxentlabs: https://www.marxentlabs.com/what-is-virtual-reality/

[5] Beste, A. $(2015,12,14)$. Education in Emergencies: Will Syrian Refugee Children Become a 'Lost Generation'? Retrieved from Our world: https://ourworld.unu.edu/en/education-in-emergencies-will-syrian-refugee-children-become-a-lost-generation\#: : text=In $\% 202014 \% 20$ less $\% 20$ than $\% 2045$,regardless $\% 20$ of $\% 20$ their $\% 20$ legal $\% 20$ status.\&text=The $\% 20$ government $\% 20$ has $\% 20$ set\%20up,of\%20non\%2Dformal\%20education\%

[6] Brown, G. (2016, February 22). How virtual education is helping refugee children. Retrieved from World economic forum: https://www.weforum.org/agenda/2016/02/how-virtual-education-is-helping-refugee-children

[7] German education adapts to include refugees in the classroom. (n.d.). Retrieved from education for refugees: include training in language skills as well as vocational, academic, and political education.

[8] Gupton, N. (2017, September 21). WHAT'S THE DIFFERENCE BETWEEN AR, VR, AND MR? Retrieved from THE FRANKLIN INSTITUTE: https://www.fi.edu/difference-between-ar-vr-and-mr\#: :text=Augmented\%20reality\%20(AR)\%20adds\%20digital,shuts\%20out\%20the\%20physical\%20world.

[9] Picheta, R. (2020, January 24). Young refugees in Kenya take a VR school trip to London's National Gallery. Retrieved from CNN: https://edition.cnn.com/2020/01/24/africa/kenya-refugees-vr-school-trip-scli-intl/index.html

[10] Plan-international.org. (n.d.). EDUCATION IN JORDAN. Retrieved from PLan International: https://plan-international.org/jordan/education-jordan

[11] Turkey: Refugee children build their own virtual reality city. (2018, February 28). Retrieved from UNHCR: https://www.unhcr.org/news/videos/2018/2/5a8550104/turkey-refugee-children-build-their-own-virtual-reality-city.html. 